\title{
Global distribution of snow avalanches and changing activity in the Northern Hemisphere due to climate change
}

\author{
T. G. Glazovskaya \\ Laboratory of Snow Avalanches and Mudflows, Department of Geography, Moscow State University, 119899 Moscow, Russia
}

\begin{abstract}
Snow avalanches occur in the mountains of all continents and climatic zones. The lower boundary of avalanche distribution rises from sea level in polar and temperate zones to $6000 \mathrm{~m}$ in the tropics. Four altitudinal belts of avalanching are distinguished: (I) permanent snow; (II) stable seasonal snow cover; (III) unstable snow cover; and (IV) rare snowfalls. Most avalanche-danger areas of the world belong to the stable seasonal snow-cover belt.

Using data from a GFDL $Q$-flux Model, we estimated possible changes of the main characteristics of the avalanche regime in the Northern Hemisphere: depth of snow cover, duration of the avalanche-prone period and number of days with avalanche-prone snowfalls. At the beginning of the twenty-first century, there will likely be a smoothing of the sharp differences in avalanche activity between various mountain regions of the World. Avalanche activity should be less in the most active regions and it is likely to increase in regions with low avalanche activity.
\end{abstract}

\section{INTRODUGTION}

Creation of an atlas of snow and ice resources of the World was initiated in the former Soviet Union (FSU) by V. M. Kotlyakov in the 1970s. The new technique of avalanche mapping was developed at the Laboratory of Snow Avalanches and Mudflows of Moscow State University. Maps of the degree of avalanche activity, climatic factors of ava- lanching, frequencies of avalanche occurrence and volumes were composed for the mountains of the World. These maps made it possible to evaluate the global distribution of avalanches and their regime.

Avalanche-danger regions cover about $6 \%$ of the Earth's land area. They occur on all continents, in all climatic belts and high-altitude zones (Fig. 1) (Myagkov and Kanaev, 1992). In the former Soviet Union (FSU) they occupy about

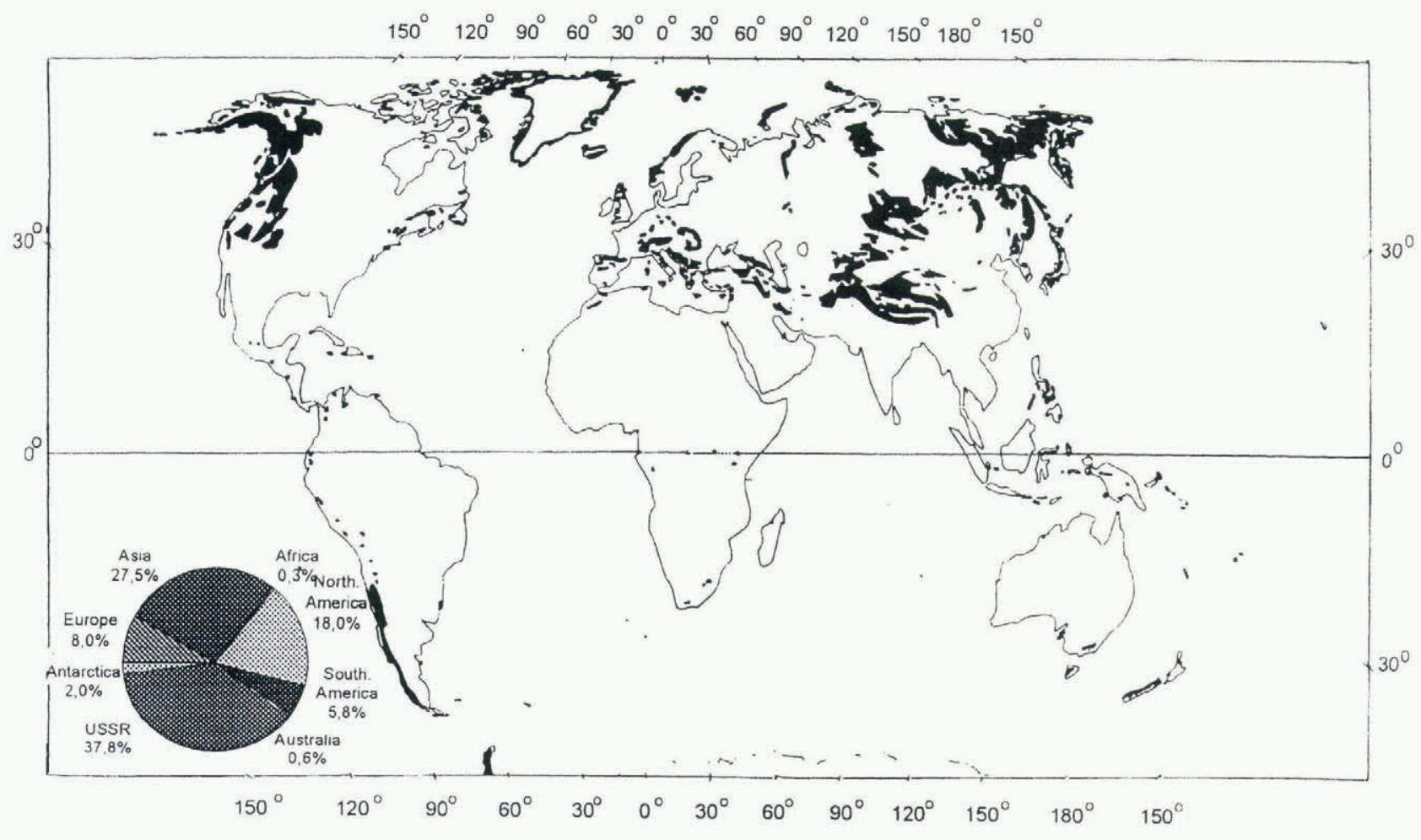

Fig. 1. Avalanche-prone regions of the World. 
$3.5 \times 10^{6} \mathrm{~km}^{2}$ or $15.6 \%$ of its area. The FSU had almost $40 \%$ of the avalanche-danger zones of the World (see inset in Fig. 1).

The same technique was used to estimate possible changes of the avalanche regime that might result from global climatic change and we report here results for a doubling of $\mathrm{CO}_{2}$.

\section{DEGREE OF ACTIVITY}

The sizes of the areas with different degrees of avalanche activity on the continents are, in general, not equal, but the territories with different degrees of avalanche activity in western Europe are almost equal. In Asia (outside the FSU) and South America, a low degree of avalanche activity (almost half of all avalanche-danger areas) prevails; in Africa and in Australia it is average to low and in North America and in New Zealand it is high. In the FSU, mountain territories occupy nearly one-third of the area, and almost half of it is endangered by avalanches.

\section{REGIME}

The distribution of the factors of avalanche formation and of other characteristics of avalanches is restricted to high-altitude belts and latitudinal zones. We have determined four high-altitude belts of avalanche formation: permanent snow, stable and unstable seasonal snow cover and rare snowfalls. The two last high-altitude belts occur only in mountains which are surrounded by snowless plains, e.g. in the sub-tropics and closer to the Equator. Because of the absence of winters in the Equatorial climatic zone, there is no stable seasonal snow cover there.

Most avalanche-danger regions of the World lie in the belt of persistent winter snow cover, for which the greatest variability of the avalanching factors and high values for parameters of the avalanche regime are common. However, the most unexpected and catastrophic avalanches occur in the belt of unstable snow cover and rare snowfalls, for example in Turkey, Africa and in the Little Caucasus.

In the Equatorial belt, the potential danger due to avalanches can occur at any time of the year. The duration of the avalanche-danger period in the belt of unstable snow cover is more than 1 month. During these periods, the main factors of avalanche formation are heavy, damp snowfalls and thawing periods; the number of days with avalanches caused by snowfalls is between 1 and 3 . The lower limit of the distribution of avalanches in this zone is between 3000$4000 \mathrm{~m}$ a.s.l. Figure 2 demonstrates (i) the latitudinal changes of position of the lower boundary of the distribution of avalanches in the different climatic belts, and (ii) the distribution of traces of this limit according to their position in different types of climate, either marine or continental.

In the sub-Equatorial belt, the avalanche danger is greatest during summer. The duration of the avalanchedanger period here may last as long as 3 months and the number of days with avalanches caused by snowfalls may be as high as 10-15 (on the southern slopes of the Himalaya). The lower limit of the avalanche belt lies from 2000$4000 \mathrm{~m}$ a.s.l., but in the area of especially damp monsoons (Himalaya) it can be as low as $1000 \mathrm{~m}$. The main factors influencing avalanches are snowfalls, snowstorms and thaws.

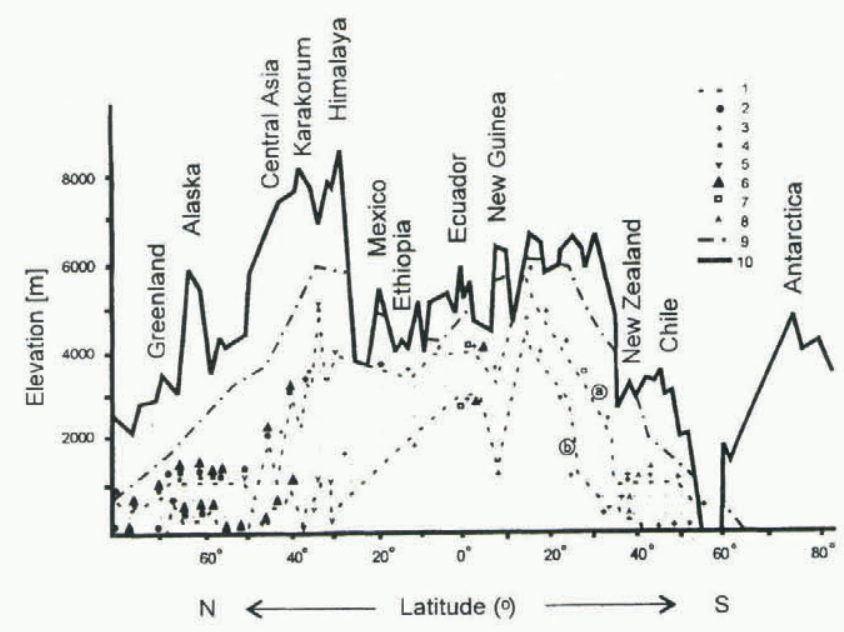

Fig. 2. Position of the lower boundary of snow avalanches in the mountain systems of the World, in latitudinal belts (1): $a$, maximum; $b$, minimum over the territory of North America (2), South America (3), Europe (4), Asia (5), former U.S.S.R. (6), Africa (7), Australia, New Zealand and New Guinea (8) The greatest altitude of the seasonal snowline (9); schematic vertical section of mountain summits (10).

In the tropics, mountain regions are sharply distinguished by the amount of precipitation. Thus, in the central Andes precipitation is very low; the number of days with avalanches caused by snowfalls is $1-3$; the lower limit of the avalanching belt here is the highest in the World, 5000$6000 \mathrm{~m}$, and the avalanche hazard occurs during snowstorms. Examples of regions with abundant precipitation are the mountains of southern Mexico (Volcanic Sierra). The lower limit of the avalanche belt there is at about $3700 \mathrm{~m}$.

In the sub-tropical belt, snowfall can occur in the foothills. This belt differs from others in its large seasonal variations of temperature and precipitation. Three types of climate prevail: the western and eastern coasts of the continents and the continental areas. In the mountains of the first type, the duration of the avalanche-danger period is more than 1 month and in the high Chilean Andes it lasts as long as 7 months. The lower limit of avalanches is at a height of $2000-3000 \mathrm{~m}$ and the main factors in avalanche formation are snowfalls and snowstorms. In the mountains of the second type (east coast), the duration of the avalanche period is about 1 month, and the lower limit is at $500-1000 \mathrm{~m}$. In the mountains with a continental sub-tropical climate, the number of days with avalanches caused by snowfall reaches $15-20$, and the duration of the periods with an avalanche hazard is 5 and more months (upper part of the central Asian mountains). The large spread in the lower limit of avalanches, from 500 to $5000 \mathrm{~m}$, is explained by the different exposures and distances of the various regions from the ocean. The main factors of avalanche formation here again are snowstorms and snowfalls and, at elevations higher than $5000 \mathrm{~m}$ in internal regions of Asia, the metamorphism of snow.

The regions threatened with the largest number of avalanches are located in the temperate belt. Here, as well as closer to the poles, the lower boundary of avalanche distribution may be as low as sea-level. Therefore, on all maritime coasts, even at relatively low altitudes $(50-70 \mathrm{~m})$ abrasion shores are avalanche-prone areas. In this belt, three types of climate arise; however, the principal factors of avalanche 

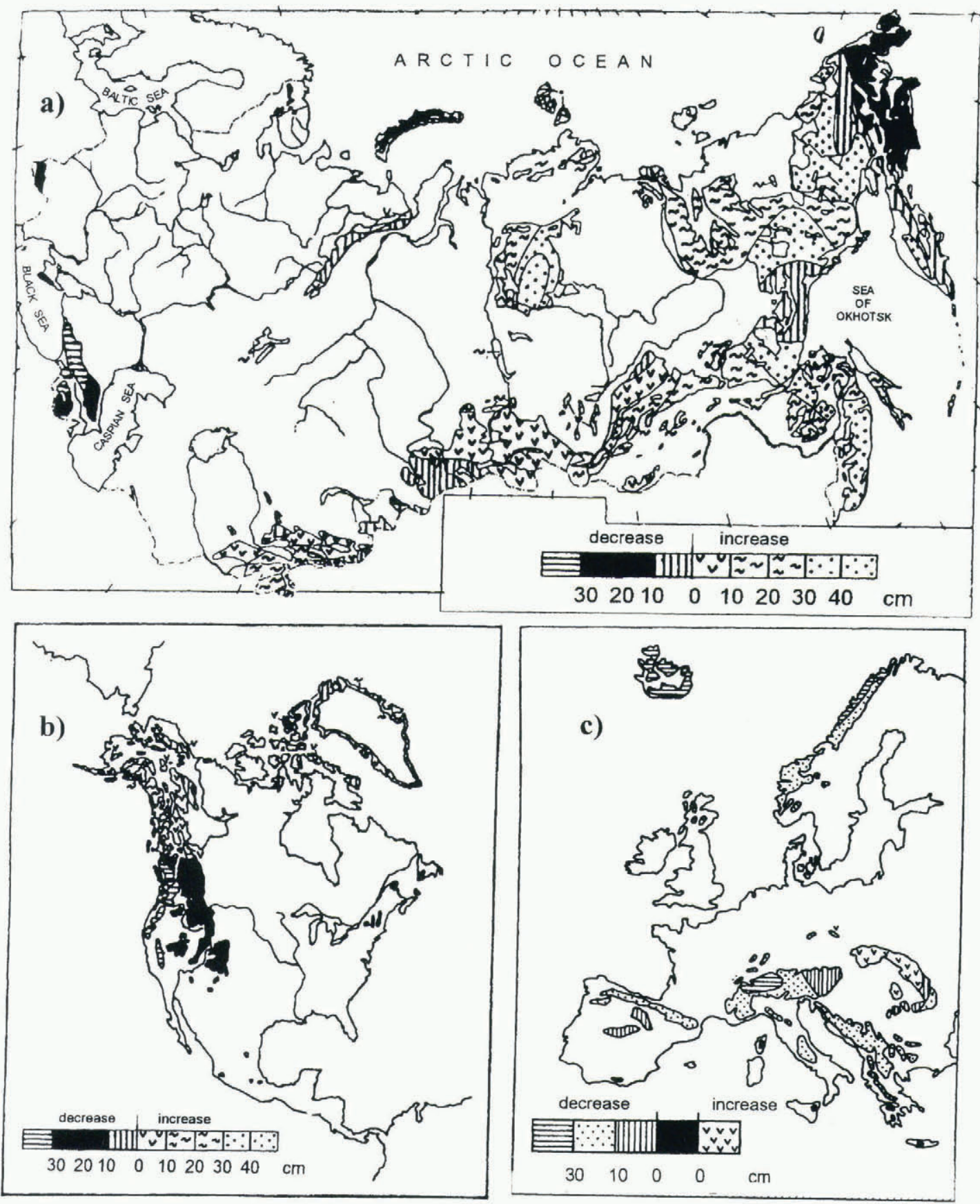

Fig. 3. Possible change of snow depth (cm) due to a global warming $\left(2 \times \mathrm{CO}_{2}\right):($ a $)$ former Soviet Union; ( $b$ ) North America; (c) Europe.

formation for these types of climate are numerous. In lowsnow and cold intra-continental regions, metamorphism of snow as well as snowstorms play a significant role. For regions with a marine climate, avalanches from fresh snow typically occur.

In sub-polar and the polar belts, avalanche frequency is less than in temperate zones but they do occur throughout the year; the leading factors of avalanche formation are snowstorms and the metamorphism of snow.

\section{CHANGES OF AVALANCHE ACTIVITY DUE TO GLOBAL WARMING}

In past decades, the number of avalanche accidents has grown; related economic damage and the number of victims have also increased. This is not only connected to intensive mountain exploration but also to changes in avalanche activity.

To investigate changes of some characteristics of the avalanche regime which may be due to global climate change, we chose the general circulation model constructed by the Geophysical Fluid Dynamics Laboratory of NOAA, Princeton (GFDL 1988(Q-flux Mode)). The GFDL model used takes into account surface air temperature, surface ground temperature, total monthly averaged precipitation per day, winds, mixing ratio, soil moisture, etc.; then, the model calculates a monthly average air temperature and precipitation for the present and for when atmospheric $\mathrm{CO}_{2}$ will be doubled. Since the data are obtained within a $4.5^{\circ}$ lat. $\times 7.5^{\circ}$ long. grid resolution, it has been used not only for a global but also for a regional study.

We determined avalanche indicators using standard meteorological data, developed to map avalanches in for- 

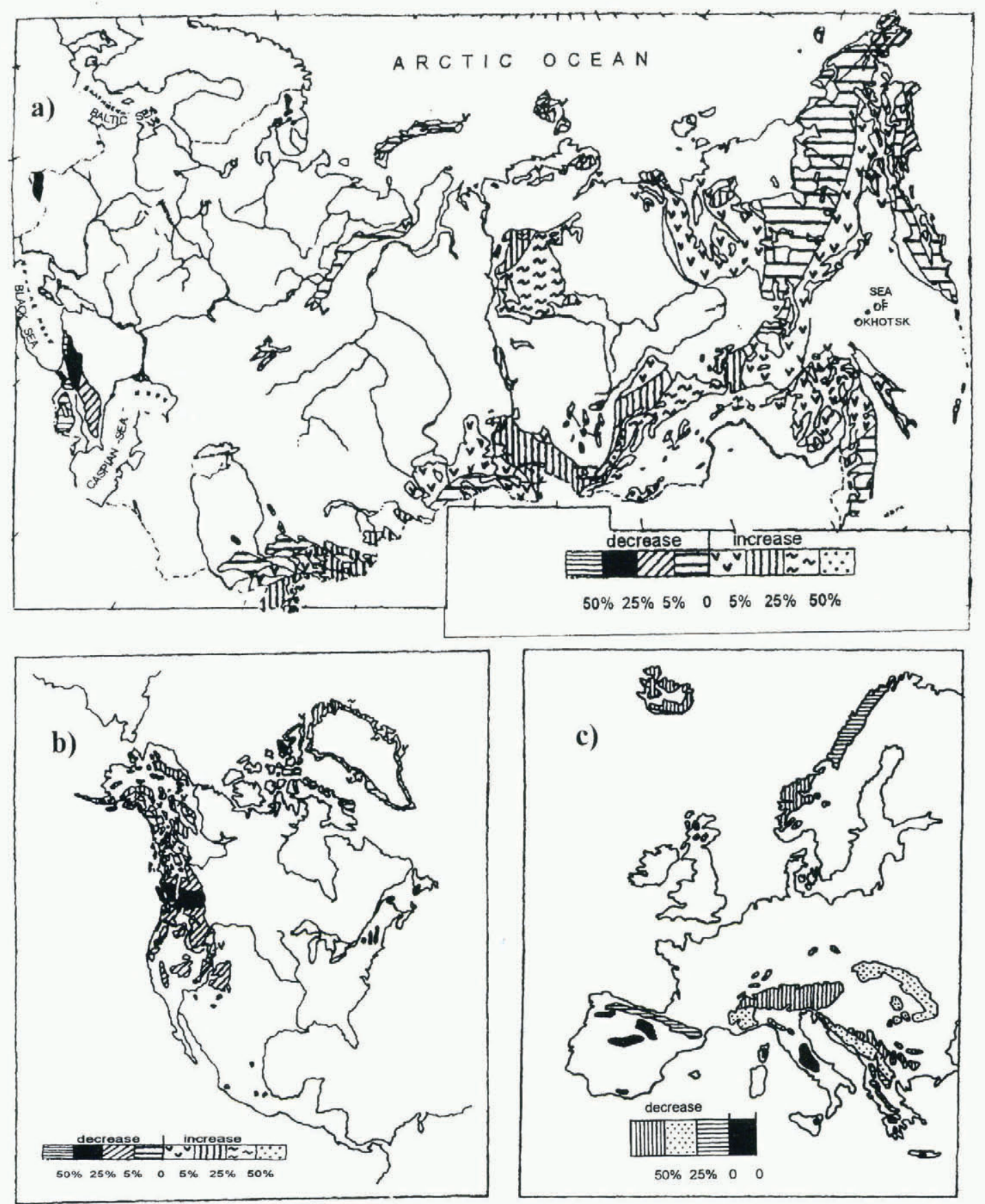

Fig. 4. Possible change in number of days with snowfall more than $10 \mathrm{~mm}(\%)$ due to a global warming $\left(2 \times \mathrm{CO}_{2}\right):($ a) former Soviet Union; (b) North America; (c) Europe.

eign territories for the atlas of snow and ice resources of the World (Glazovskaya and others, 1978). In this study, we chose three large regions of the Northern HemisphereNorth America, western Europe and the territory of the FSU.

The following key parameters of the avalanche regime were determined:

Depth of the snow cover (which determines the borders of avalanche-hazard regions, avalanche volumes and to a certain extent the repeatability of avalanches).

Number of days with snowfall $>10 \mathrm{~mm} \mathrm{~d}^{-1}$ (heavy snowfalls are one of the main factors for avalanches).

Duration of the avalanche-prone period.

Maps showing changes in these characteristics were also compiled.
One scenario of a possible change in snow-cover depth (Fig. 3) shows that the maximum reduction $(>30 \mathrm{~cm})$ is expected in coastal ranges, which are today's heavy snow regions. In the FSU, it is the western Caucasus; in North America, the western Coast Ranges of Canada, the southern cordillera and the Appalachian Mountains. Quite to the contrary, a maximum increase also occurs in the continental regions: in the FSU - in Plato Putorana and the eastern Pamir, in North America, and along the dry east coast of Greenland (annual precipitation: $100-250 \mathrm{~mm}$ ). In the FSU, those regions where the depth of the snow cover and the avalanche hazard increases are greater than those where it is reduced. In North America, the opposite tendency has been observed. In southern Europe, in some avalancheprone regions (e.g. Sierra Nevada, Corsica, Etna and in Greece) no change in snow-cover depth is predicted. Only in the Carpathians might a small increase of snow depth 

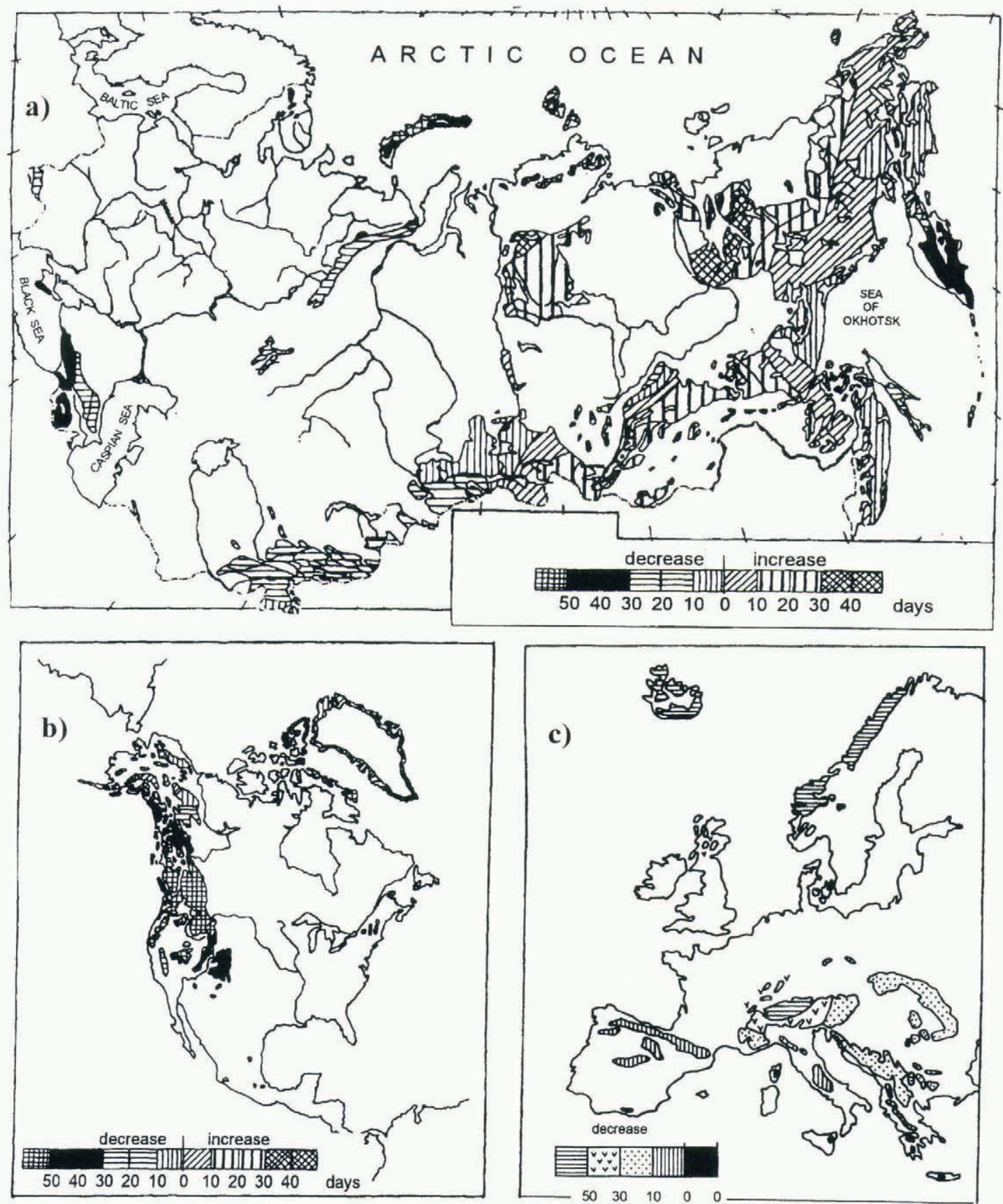

Fig. 5. Possible change of avalanche-prone period duration (d) due to global warming $\left(2 \times \mathrm{CO}_{2}\right)$ : (a) former Soviet Union; (b) North America; (c) Europe.

(up to $10 \mathrm{~cm}$ ) occur. In other mountainous regions, the snow depth is expected to decline with a maximum reduction $(>30 \mathrm{~cm})$ expected in Iceland, in northern Scandinavia and in the central Alps.

The change in the number of days with intensive snowfall (more than $10 \mathrm{~mm} \mathrm{~d}^{-1}$ ) is shown in Figure 4. The same trends are seen as in the previous case. The greatest change in a parameter (more than 25-50\%) is expected in the western Caucasus, in the Trans-Caucasus of the FSU and in the western mountains of Canada and the southern cordillera of North America. The maximum increase is found in the continental regions of middle Siberia (Putorana) and in Zabaikalie, as well as in the eastern Pamir of the FSU and along the east coast of Greenland. In western Europe, one might expect a reduction in the days with intense snowfalls; the maximum reduction $(>50 \%)$ will likely occur in Ice- land, southern Scandinavia and in the central and eastern Alps. In the Spanish mountains, in Corsica, in the Apennines, on Etna and in Greece no change is predicted.

The general picture of the change in avalanche periods (Fig. 5) is little different from that of the two previous parameters. An increase is not likely in the territory of the FSU, and avalanches are expected to decrease in North America. The regions with the greatest reduction (change in a period of up to 50 days) are more likely to be those in the north than in the previous cases. In the FSU, it is Novaya Zemlya; in North America, the Canadian cordillera. A possible reduction in avalanche periods is expected in all avalanche regions of western Europe with a maximum in Iceland, Scandinavia and the central Alps. Only in the southern mountains of Spain, on Etna and in Greece, will the duration of an avalanche period remain the same as today. 


\section{GONCLUSION}

As an overall conclusion, we can infer that with a global change of climate, all three parameters will significantly change:

There will be a reduction in the present heavy snow regions: for the FSU, in Khibinas, Carpathians and, in particular, in the Caucasus; in North America, in the Appalachians, in the Canadian cordillera and, in particular, in the Coast Ranges; in western Europe in nearly all mountainous regions, particularly in Iceland and in the central Alps.

There will be an increase in today's low-snow regions: in the FSU, in the continental regions of Siberia (Putorana, the mountains of Yakutia and southern Zabaikalie); and along the east coast of Greenland.

On the basis of this study, we conclude that, at the beginning of the twenty-first century, differences in avalanche activities between the various mountainous regions of the World will be smoothed. Avalanche activity will decrease in most of today's active regions and increase in those regions with low activity.
These computed changes in avalanche regime correspond to maximum changes, because in the GFDL models maximum changes in air temperature $\left(3.5^{-} 4^{\circ} \mathrm{C}\right)$ were considered.

\section{ACKNOWLEDGEMENTS}

This work was supported by the Russian Fund of Fundamental Investigations.

\section{REFERENCES}

Geophysical Fluid Dynamics Laboratory (GFDL). 1988. GFDLQ-flux model. Princeton, NJ, Princeton University. Geophysical Fluid Dynamics Laboratory.

Glazovskaya, T. G., S. M. Myagkov and V. F. Okolov. 1978. Vozmoshnaya metodica sostavleniya kart lavinnoy opasnosti v Atlase sneshno-ledovih resursov mira na zarubeshniye territorii [Methods of compiling avalanche-hazard maps of foreign territories for the world atlas of snow and ice resources]. Mater. Glyatsiol. Issled. 34, 50-58.

Myagkov, S. M. and L. A. Kanaev. 1992. Geografiya lavin [Geography of avalanches 7. Moscow, Moskovskogo Universiteta. 